\title{
Improvement in appropriateness and diagnostic yield of fast-track endoscopy during the COVID-19 pandemic in Northern Italy
}

\author{
Authors \\ Gianpiero Manes,2, Simone Saibeni ${ }^{1,2}$, Lucienne Pellegrini ${ }^{1,2}$, Desiree Picasciaa,2, Fabio Pace ${ }^{3}$, Mario Schettino ${ }^{1,2}$, \\ Cristina Bezzio ${ }^{1,2}$, Germana de Nucci ${ }^{1,2}$, Cesare Hassan ${ }^{4}$, Alessandro Repici ${ }^{5}$, and The Fast-Track Endoscopy Study \\ Group \\ Institutions \\ 1 ASST Rhodense, Gastroenterology and Endoscopy Unit, \\ Garbagnate Milanese, Milan, Italy \\ 2 ASST Rhodense, Gastroenterology and Endoscopy Unit, \\ Rho, Milan, Italy \\ 3 Bolognini Hospital, Gastroenterology Unit, Seriate, Italy \\ 4 Gastroenterology Unit, Nuovo Regina Margherita \\ Hospital, Rome, Italy \\ 5 Humanitas University, Department of Biomedical \\ Sciences, Rozzano, Milan, Italy \\ submitted 24.6.2020 \\ accepted after revision 17.9.2020 \\ published online 17.9.2020 \\ Bibliography \\ Endoscopy 2021; 53: 162-165 \\ DOI 10.1055/a-1265-3315 \\ ISSN 0013-726X \\ (C) 2020. Thieme. All rights reserved. \\ Georg Thieme Verlag KG, Rüdigerstraße 14, \\ 70469 Stuttgart, Germany \\ \# Supplementary material \\ Supplementary material is available under \\ https://doi.org/10.1055/a-1265-3315 \\ Corresponding author \\ Gianpiero Manes, MD, Department of Gastroenterology and \\ Endoscopy, ASST Rhodense, Garbagnate Milanese and Rho \\ Hospitals, Viale Forlanini 95, 20024 Garbagnate Milanese, \\ Milan, Italy \\ Fax: +39-02-994301905 \\ gmanes@asst-rhodense.it

\section{ABSTRACT} \\ Background During the COVID-19 outbreak in Italy, only \\ fast-track endoscopic procedures have been performed; \\ nevertheless, a significant drop in their number has been \\ reported. We evaluated whether the pandemic has impac- \\ ted the appropriateness and diagnostic yield of fast-track \\ endoscopic procedures compared with those performed in \\ 2019. \\ Methods This retrospective study involved endoscopy ser- \\ vices in Northern Italy. We compared data regarding endo- \\ scopic procedures performed in March and April 2020 with \\ those performed during the same period in 2019. \\ Results In 2020, there was a $53.6 \%$ reduction in the num- \\ ber of fast-track endoscopic procedures compared with \\ 2019. Patients undergoing endoscopy in 2020 were young- \\ er than in 2019. Both appropriate referral and diagnostic \\ yield increased in 2020 for both upper and lower endos- \\ copy. A higher rate of cancer was diagnosed in 2020 by up- \\ per endoscopy (3.6\% vs. $6.6 \%$; $P=0.04$ ). \\ Conclusions The high level of inappropriate endoscopy re- \\ ferrals registered in 2019 significantly improved during the \\ COVID-19 outbreak of 2020, with an increase in the diag- \\ nostic yield.
}

\section{Introduction}

Gastrointestinal (GI) endoscopy is used in clinical practice for diagnosis, surveillance, treatment, or exclusion of relevant diseases. In Northern Italy, general practitioners or other specialists can refer patients for GI endoscopy. The Italian National Health System classifies medical procedures into four categories: class $\mathrm{U}$, due in 72 hours, for life-threatening situations; class B, due in
10 days, for patients with a suspected condition, the diagnosis of which should not be delayed; class D, due in 60 days; and class P, to be performed within 6 months (see Fig. $1 \mathrm{~s}$ in the online-only supplementary material). Endoscopy services will reserve places for $\mathrm{U}$ and $\mathrm{B}$ priority classes, but inappropriate patient allocation is common and results in the misuse of resources [1,2]. Inappropriate $\mathrm{Gl}$ endoscopies achieve low diagnostic yield and result in considerable increases in both costs and waiting lists [3]. Pos- 
sible explanations for the high number of inappropriate endoscopies are overinterpretation of symptoms by general practitioners and the pressure exerted by patients on referring physicians [4, 5]. In Italy, during the COVID-19 outbreak in 2020, only $\mathrm{U}$ - and B-class procedures have been performed [6]; nevertheless, as the infection spread, a significant drop in the number of these procedures has been reported [7].

We conducted this study to evaluate the impact of the COVID-19 pandemic on the appropriateness and diagnostic yield of $\mathrm{U}$ - and B-class endoscopic procedures in Northern Italy.

\section{Methods}

This was a retrospective study involving eight endoscopy services in Northern Italy, performing more than 5000 procedures per year. In each center, the following data were collected from medical charts: age, sex, type of endoscopic procedure, indication for endoscopy, and endoscopic findings. Appropriateness of each referral was evaluated by a single endoscopist at each center who, in accordance with the American Society for Gastrointestinal Endoscopy (ASGE) guidelines [8] (Table 1s), assessed the indications by comparing the history obtained from patients with that reported on the referral cards.

Demographic details, indications, appropriateness, and endoscopic findings of the $\mathrm{U}$ - and B-class endoscopic procedures performed in March and April 2020 were compared with those performed during the same period in 2019. Approval from institutional review boards was obtained for the study. The requirement for informed consent was waived because this was a retrospective, observational study and patients' privacy was guaranteed.

Data were analyzed using SPSS 26.0 (IBM Corp., Armonk, New York, USA). Continuous variables are presented as mean and standard deviation (SD), and categorical variables as absolute frequency and percentage. We used Student's $t$ test to compare quantitative variables and $\mathrm{X}^{2}$ test for qualitative ones. Odds ratio (OR) and $95 \%$ confidence interval $(\mathrm{Cl})$ were reported for data analysis. All differences were considered significant at two-sided $P$ value.

\section{Results}

We observed a reduction of $53.6 \%$ in the number of fast-track endoscopic procedures performed in 2020 compared with 2019 (688 vs. 1481), which was more evident in upper GI endoscopy (UGIE) procedures (287 vs. $666,56.9 \%$ reduction) than in lower GI endoscopy (LGIE) procedures (401 vs. 815 , $50.8 \%$ reduction). Patients undergoing endoscopy in 2020 were younger than those in 2019 , with a slight, but not significant, prevalence of males (Table $2 \mathbf{s}$ ).

The main indications for endoscopy in the two groups are reported in Table $3 \mathrm{~s}$. Dyspeptic symptoms and a positive fecal occult blood test were the most frequent symptoms for IGIE and LGIE, respectively, both in 2019 and 2020. Alarm symptoms represented about $39.5 \%(263 / 666)$ of all indications for UGIE in 2019 and increased to $44.3 \%(127 / 287)$ in $2020(P=0.03)$. For LGIE procedures, $65.9 \%$ (537/815) of indications were repre- sented by alarm symptoms in 2019, with no significant increase in 2020 (70.3\%; 282/401).

The rate of appropriate referral significantly increased from $57.1 \%$ in 2019 to $66.6 \%$ in 2020 (OR 0.67, $95 \% \mathrm{Cl} 0.55-0.81$; $P$ $<0.001)$ and was evident for both UGIE (306/666 [45.9\%] vs. $161 / 287$ [56.1\%]; OR 0.68, 95\%Cl 0.51-0.89; $P<0.001)$ and LGIE (540/815 [66.3\%] vs. 297/401 [74.1\%]; OR 0.69, $95 \% \mathrm{Cl}$ $0.53-0.90 ; P=0.006$ ) (Table 3 s).

The main endoscopic findings are shown in > Table 1 and - Fig. 1. The diagnostic yield (the rate of relevant diagnoses achieved by endoscopy) was $29.4 \%(435 / 1481)$ in 2019 vs. $38.7 \%(266 / 688)$ in 2020 (OR 0.66, 95\%Cl 0.55-0.80; $P<$ $0.001)$, with similar results for UGIE (23.9\% vs. $35.5 \%$; OR $0.57,95 \% \mathrm{Cl} 0.42-0.77 ; P<0.001)$ and LGIE (33.9\% vs. $40.9 \%$; OR $0.74,95 \% \mathrm{Cl} 0.58-0.95 ; P=0.01)$. Overall, cancer diagnosis was achieved in $7.3 \%$ of procedures in 2020 vs. $6.0 \%$ in 2019 (OR $0.83,95 \% \mathrm{Cl} 0.58-1.18 ; P=0.2$ ). However, a significantly higher rate of cancer was diagnosed in 2020 by UGIE ( $3.6 \%$ vs. $6.6 \%$; OR 0.53, $95 \% \mathrm{Cl} 0.28-0.98 ; P=0.04$ ).

\section{Discussion}

Our study shows that during the pandemic in 2020 the number of endoscopic procedures significantly decreased while the rate of appropriate referral and of relevant findings improved compared with the same period in 2019. As availability and ease of access to $\mathrm{U}$ - and $\mathrm{B}$-class procedures during the pandemic have not changed from previous years, we can hypothesize that patients' and physicians' perceptions toward the risk of COVID-19 exposure could have limited the number of inappropriate procedures. Of note, the rate of inappropriate fast-track procedures registered in the 2019 study period was about $40 \%$, and this rate was higher at $54 \%$ for UGIE procedures. This situation could overload endoscopy services with a high number of unnecessary procedures and potentially delay diagnosis for high-risk patients.

Concern about potential medicolegal consequences related to a possible delayed diagnosis is a common cause of overinterpretation of patient symptoms and over-referral for endoscopic procedures by general practitioners $[1,2,4]$. During the outbreak, new concerns about patients acquiring the infection while undergoing a potentially inappropriate procedure has likely prevailed and has resulted in fewer patient referrals; a concern also shared by patients themselves, who were less likely to attend endoscopy services or even general practitioners' offices [7]. Patients, particularly those affected by functional pathology, frequently exert considerable pressure on general practitioners and specialist services to undergo endoscopy for their symptoms [5]. It is conceivable that, during the pandemic, such pressure might have decreased because patients' attention was diverted from their Gl symptoms to the risk of infection; this is probably more evident in patients with functional disease who often suffer from generalized anxiety disorders [9]. Of note, patients with no alarm signs, who ask to shorten their endoscopy waiting time due to anxiety, do not represent a high-risk category for major organic pathology and anticipating their endoscopy determines a very low diagnostic gain [10]. 
- Table 1 Major endoscopic findings in patients undergoing endoscopy in 2019 and 2020. Only one finding is reported for each patient. Significant data are depicted in bold.

\begin{tabular}{|c|c|c|c|}
\hline Endoscopic findings & 2019, n (\%) & $2020, n(\%)$ & $P$ value (OR, $95 \% \mathrm{Cl})$ \\
\hline Upper GI Endoscopy & $n=666$ & $n=287$ & \\
\hline \multicolumn{4}{|l|}{ Not relevant diagnoses- } \\
\hline - Normal ${ }^{1}$ & $487(73.1)$ & 169 (58.9) & $<0.001(1.90,1.42-2.54)$ \\
\hline - Other ${ }^{2}$ & $20(3)$ & $16(5.6)$ & $0.06(0.52,0.27-1.02)$ \\
\hline \multicolumn{4}{|l|}{ Relevant diagnoses } \\
\hline - Erosive esophagitis/Barrett's & $66(9.9)$ & $35(12.2)$ & $0.3(0.79,0.51-1.22)$ \\
\hline - Peptic ulcer & $44(6.6)$ & $15(5.2)$ & $0.4(1.28,0.70-2.34)$ \\
\hline - Esophageal/gastric cancer & $24(3.6)$ & $19(6.6)$ & $0.04(0.53,0.28-0.98)$ \\
\hline - Benign stenosis & $9(1.8)$ & $22(7.7)$ & $<0.001(0.16,0.07-0.36)$ \\
\hline - Other ${ }^{3}$ & $16(2.4)$ & $11(3.8)$ & $0.2(0.62,0.28-1.34)$ \\
\hline Lower GI Endoscopy & $n=815$ & $\mathrm{n}=401$ & \\
\hline \multicolumn{4}{|l|}{ Not relevant diagnoses } \\
\hline - Normal ${ }^{4}$ & $478(58.6)$ & $216(53.9)$ & $0.1(1.21,0.95-1.54)$ \\
\hline - Low risk adenoma & $38(4.7)$ & $11(2.7)$ & $0.1(1.73,0.88-3.43)$ \\
\hline - Other ${ }^{5}$ & $23(2.8)$ & $10(2.5)$ & $0.7(1.13,0.53-2.40)$ \\
\hline \multicolumn{4}{|l|}{ Relevant diagnoses } \\
\hline - Advanced adenoma & $150(18.4)$ & $90(22.4)$ & $0.09(0.78,0.58-1.05)$ \\
\hline - IBD & $49(6)$ & $38(9.5)$ & $0.02(0.61,0.39-0.95)$ \\
\hline - Colon cancer & $65(8)$ & $31(7.7)$ & $0.9(1.03,0.66-1.61)$ \\
\hline - Other ${ }^{6}$ & $12(1.5)$ & $5(1.2)$ & $0.7(1.8,0.41-3.38)$ \\
\hline \multicolumn{4}{|c|}{$\begin{array}{l}\text { OR, odds ratio; Cl, confidence interval; GI, gastrointestinal; IBD, inflammatory bowel disease. } \\
{ }^{1} \text { Normal finding includes nonerosive gastritis/duodenitis, hiatal hernia. } \\
2 \text { Other includes fundic gland polyps, gastric resected stomach. } \\
{ }^{3} \text { Other includes varices, portal hypertensive gastropathy, celiac disease, fistula. } \\
{ }^{4} \text { Normal includes diverticulosis. } \\
{ }^{5} \text { Other includes hyperplastic polyps, not specific inflammation. } \\
{ }^{6} \text { Other includes fistula, benign stenosis, solitary rectal ulcer, angiodysplasia, diverticulitis, other specific colitis. }\end{array}$} \\
\hline
\end{tabular}

Rex et al. have reported that during the pandemic, $44 \%$ of patients scheduled for endoscopy were very or somewhat concerned about acquiring the infection, while $25 \%$ were quite unsure or not willing at all to undergo endoscopy [11]. In an emerging epidemic, human behavioral changes are driven by risk perceptions $[7,12,13]$, which are also related to the psychological status of the patient, self-perception of vulnerability, and perceived severity of symptoms. Our finding that patients attending endoscopy during the pandemic were younger than in 2019 might be explained by elderly patients having a perceived higher risk of developing a more severe infection. Moreover, the improvement in appropriateness recorded in 2020 was highly evident for patients undergoing endoscopy for symptoms usually related to functional disease: about $51 \%$ of patients undergoing UGIE in 2019 presented dyspeptic symptoms with a level of appropriateness of only 17\%; in 2020 dyspeptic symptoms still represented about $44 \%$ of the indications, but the level of appropriateness had increased to $30 \%$. Similarly, ab- dominal pain, diarrhea, and constipation together represented the indications for LGIE in $23 \%$ and $16 \%$ of patients in 2019 and 2020 , respectively, but the level of appropriateness increased from $27 \%$ in 2019 to $41 \%$ in 2020 .

We reported a decrease of about $50 \%$ in fast-track procedures performed in 2020 compared with 2019, while appropriateness increased by only about $10 \%$. This finding suggests that several potentially appropriate procedures may not have been performed. Indeed, the overall number of cancer diagnoses decreased in 2020 compared with 2019, from 24 to 19 in the upper $\mathrm{Gl}$ tract and from 65 to 31 in the lower GI tract. A delayed diagnosis of malignancy will likely occur in several patients due to the pandemic [14], but we will only be able to verify this in the coming months.

This study has some limitations in addition to its retrospective design. First, fast-track procedures are usually indicated only when alarm symptoms are present. Furthermore, patients with mild symptoms may not have sought medical attention during 


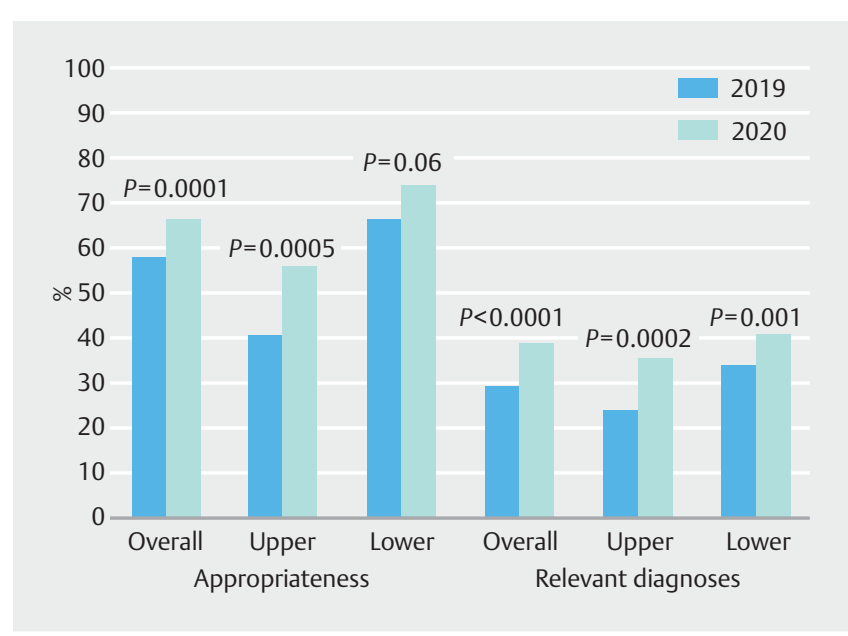

- Fig. 1 Appropriateness and relevant diagnoses of fast-track endoscopic procedures performed during the COVID-19 pandemic in 2020 and in the same period in 2019.

the COVID pandemic. This would result in referral bias for moderate to severe cases, and therefore the data are not easily generalizable. Second, in the absence of clear-cut criteria to define appropriateness of fast-track endoscopies $[8,15]$, we used the ASGE criteria [8], which were not designed for urgent procedures. The strengths of the study include its multicenter design and the sample size, which make the results very reproducible.

In conclusion, our study suggests that the high rate of inappropriate use of endoscopy has improved during the pandemic. The psychological impact of COVID-19 may have affected patient attitudes toward diagnostic endoscopy, especially those with functional disease. These data could help the Italian $\mathrm{Na}$ tional Health System to redesign priority classes and ensure that they are assigned correctly to improve appropriate use of endoscopy services.

\section{Acknowledgments}

The Fast-Track Endoscopy Study Group: Arnaldo Amato, Franco Radaelli (Valduce Hospital, Gastroenterology Unit, Como, Italy); Costanza Alvisi (ASST Pavia, Digestive Endoscopy Unit, Pavia, Italy, Italy); Ilaria Arena, Massimo Devani, Cristina della Corte, Enzo Mandelli, Daniela Morganti, Davide Redaelli, Raffaella Reati (ASST Rhodense, Gastroenterology and Endoscopy Unit, Garbagnate Milanese, Italy; ASST Rhodense, Gastroenterology and Endoscopy Unit, Rho, Italy); Elia Armellini, Paolo Cantù, Roberto Penagini (Fondazione IRCCS Ca' Granda Ospedale Maggiore Policlinico, Department of Gastroenterology, Milan, Italy); Lorenzo Dioscoridi, Massimiliano Mutignani (Niguarda-Ca' Granda Hospital, Digestive and Operative Endoscopy Unit, Milan, Italy); Roberto Gabbiadini (Humanitas University, Department of Biomedical Sciences, Rozzano, Italy); Venerina Imbesi (ASST Ovest Milanese, Department of Gastroenterology Ospedale di Legnano, Legnano, Italy); Pietro Occhipinti, Davide Stra- della (Department of Gastroenterology "Maggiore Della Carità" Hospital, Novara, Italy); Giovanna Venezia (Ospedale Santa Croce e Carle, Endoscopy Unit, Cuneo, Italy).

\section{Competing interests}

The authors declare that they have no conflicts of interest.

\section{References}

[1] Hassan C, Bersani G, Buri L et al. Appropriateness of upper-Gl endoscopy: an Italian survey on behalf of the Italian Society of Digestive Endoscopy. Gastrointest Endosc 2007; 65: 767-774

[2] Minoli G, Meucci G, Bortoli A et al. The ASGE guidelines for the appropriate use of colonoscopy in an open access system. Gastrointest Endosc 2000; 52: 39-44

[3] Di Giulio E, Hassan C, Pickhardt PJ et al. Cost-effectiveness of upper gastrointestinal endoscopy according to the appropriateness of the indication. Scand J Gastroenterol 2009; 44: 491-498

[4] Parente F, Bargiggia S, Bianchi Porro G. Prospective audit of gastroscopy under the 'three-day rule': a regional initiative in Italy to reduce waiting time for suspected malignancy. Aliment Pharmacol Ther 2002; 16: 1011-1014

[5] Little P, Dorward M, Warner G et al. Importance of patient pressure and perceived pressure and perceived medical need for investigations, referral and prescribing in primary care: nested observational study. BMJ 2004; 328: 444-446

[6] Repici A, Pace F, Gabbiadini R et al. Endoscopy units and the COVID-19 outbreak: a multicenter experience from Italy. Gastroenterology 2020; 159: 363-366

[7] Armellini E, Repici A, Alvisi C et al. Analysis of patients attitude to undergo urgent endoscopic procedures during COVID-19 outbreak in Italy. Dig Liv Dis 2020; 52: 695-699

[8] ASGE Standards of Practice Committee. Appropriate use of GI endoscopy. Gastrointest Endosc 2012; 75: 1127-1131

[9] Levy RL, Olden KW, Naliboff BD et al. Psychosocial aspects of the functional gastrointestinal disorders. Gastroenterology 2006; 130: 1447-1458

[10] Cardin F, Andreotti A, Zorzi M et al. Usefulness of a fast track list for anxious patients in a upper GI endoscopy. BMC Surgery 2012; 12: (Suppl. 01): S11

[11] Rex DK, Vemulapalli KC, Kane M] et al. Most patients are willing to undergo elective endoscopic procedures during the reopening period of the COVID-19 pandemic. Gastroenterology 2020; 159: 1173-1175

[12] Poletti P, Ajelli M, Merler M. Risk perception and effectiveness of uncoordinated behavioral responses in an emerging epidemic. Math Biosci 2012; 238: 80-89

[13] Cori L, Bianchi F, Cadum E et al. Risk perception and COVID-19. Int ] Environ Res Public Health 2020; 17: 3114

[14] Lui TK, Leung K, Guo CG et al. Impacts of COVID-19 pandemic on gastrointestinal endoscopy volume and diagnosis of gastric and colorectal cancers: a population-based study. Gastroenterology 2020; 159: 1164-1166

[15] Kapoor N, Bassi A, Sturgess S et al. Predictive value of alarm features in a rapid access upper gastrointestinal cancer service. Gut 2005; 54 : $40-45$ 